\title{
An investigation of flow characteristics in slope siphon drains"
}

\author{
Yue-liang CAI ${ }^{1}$, Hong-yue $\mathrm{SUN}^{\dagger \neq 2}$, Yue-quan SHANG ${ }^{1}$, Xiao-liang XIONG ${ }^{2}$ \\ $\left({ }^{1}\right.$ College of Civil Engineering and Architecture, Zhejiang University, Hangzhou 310058, China) \\ ( ${ }^{2}$ Ocean College, Zhejiang University, Hangzhou 310058, China) \\ †E-mail: shy@zju.edu.cn
}

Received May 22, 2013; Revision accepted Nov. 22, 2013; Crosschecked Dec. 19, 2013

\begin{abstract}
This paper presents a study of flow characteristics in high-lift siphon drains. A laboratory test was conducted to investigate the effects of hose diameter and flow velocity on siphon drainage. Three types of water flow were observed and analyzed. The experimental results show that the flow characteristics of siphon drainage are significantly influenced by the hose diameter. Water flows in the form of a wall pressing flow in a large diameter siphon hose (e.g., larger than $5.0 \mathrm{~mm}$ ) under low flow velocity, which leads to discontinuous siphon drainage. However, water flows in the form of an integral slug flow in a small diameter siphon hose (e.g., smaller than $4.0 \mathrm{~mm}$ ) under low flow velocity, which leads to continuous siphon drainage. Based on experimental observations, a thermodynamic derivation of the threshold of siphon hose diameter for continuous siphon drainage was analytically conducted. In slope engineering, a $3.6 \mathrm{~mm}$ polyurethane (PU) hose is recommended for siphon drainage.
\end{abstract}

Key words: Siphon drainage, Wall pressing flow, Slug flow, Siphon hose diameter, Flow characteristics doi: 10.1631 jzus.A1300178

Document code: A

\section{Introduction}

Most landslides are triggered or influenced by the rising of groundwater levels because of rainfall infiltration (Sassa, 2005; Sun et al., 2012; Shrestha et al., 2013). Positive pore pressure is the main factor governing the evolution of the entire landslide body. This is particularly true in the case of earth flows or earth slides where clay content plays a significant role. Consequently, reducing pressure is usually a main goal in achieving engineering safety. Therefore, the study of effective drainage techniques, such as siphon drainage, is essential for engineering geology and disaster prevention.

Siphon drainage can be used in slope drainage for its powerful water delivery capacity. During the siphon process, flow velocity can be controlled by automatically changing water levels. Govi (1989) and

\footnotetext{
${ }^{\ddagger}$ Corresponding author

" Project supported by the National Natural Science Foundation of China (No. 41272336), and the National Science \& Technology Pillar Program during the Twelfth Five-Year Plan Period (No. 2012BAK10B06), China (C) Zhejiang University and Springer-Verlag Berlin Heidelberg 2014
}

Cambiaghi and Schuster (1989) introduced a system using a siphon technique as an emergency drainage treatment for landslides. Currently, siphon drainage combined with electropneumatic drainage is a key method for discharging ground water in Europe, especially in France (Bertolini et al., 2005; Clark et al., 2007; Bomont, 2008; Gillarduzzi, 2008; Mrvik and Bomont, 2012). Studies have been conducted on slope siphon drainage since the 1990s, such as those on the initial siphon forming method, the maximum height limit of siphon drainage, the maintenance of siphon and management requirements. Associated engineering applications have also been developed (Zhang and Zhang, 1999a; 1999b; Yang et al., 2009; Shu and Zhang, 2005). However, the management of long-term operation of siphon techniques has not been fully explored yet.

Due to their non-persistence, siphon techniques have not yet been used widely. Generally, the solubility of a gas dissolved in liquid is proportional to the pressure acting on the liquid surface (Mao, 1987). In siphon drainage, the pressure of liquid gradually decreases with the increasing elevation over 
the liquid surface of the nozzle. Thus, during siphon processes, the air dissolved in the liquid separates out and generates bubbles, as a consequence of which, air accumulates at the tops of hoses leading to interruption of the siphon process. According to previous experiments (Sun et al., 2013), bubbles can be easily observed when the water-lift is higher than $5.4 \mathrm{~m}$, which can be defined as high-lift siphon drainage. In high-lift siphon drainage, the dramatic pressure change brings intensive air precipitation. As a result, we conclude that there are fundamental differences in physical conditions between high and low lift siphons. The water lift of an on-site low-lift siphon is a great deal lower than its maximum level. Currently, most siphon applications are associated with low-lift siphons. For high-lift drainage, exhaust devices are usually applied at the tops of the drains to prevent air accumulation (Shu and Zhang, 2005; Yang et al., 2009).

High groundwater levels and lasting intense rainfall usually lead to rapid flow rates. Previous experimental investigations (Sun et al., 2013) indicate that no air accumulates within the hoses during rapid flow rates. Therefore, continuous rainfall results in a large flow velocity and smooth drainage, whereas during long-term rainfall shortage, flow velocity slows down and bubbles accumulate. Slope drainage is a long-term process in need of enduring maintenance, which is not easily achievable.

The present paper reports an experimental investigation of the flow pattern variables and relevant influencing factors at the tops of siphon hoses. A threshold of hose diameter to maintain siphon drainage is recommended for further application.

\section{Test of siphon drainage}

Fig. 1 shows the scheme of a practical siphon drainage application. The geometric scale of sloping projects, usually in meters, contrasts starkly with that of hose cross-sections, which are usually in millimeters. Thus, the effect of the radius of curvature at the siphon hose vertex can be ignored, and the flow patterns are determined by the diameter of the hoses. Therefore, a simplified set-up was used to investigate the effect of hose diameter on flow characteristics (Fig. 2). The hose segment approaching the vertex of the siphon hose should be as straight as possible to avoid the negative impact of curvature radius.

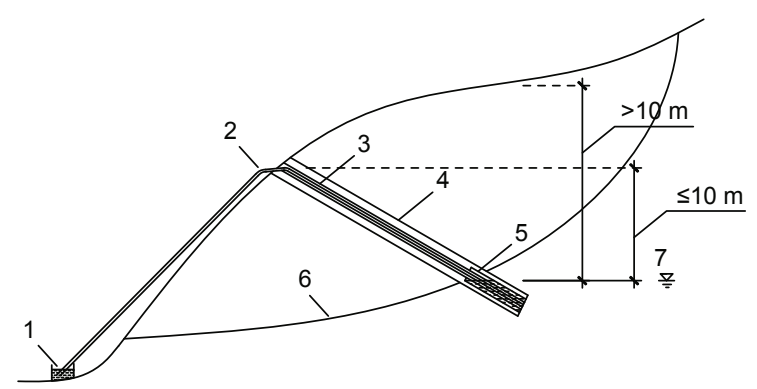

1: balance outlet; 2 : siphon drain (consist of three PU hoses); 3: pervious pipe; 4 : inclined drilling; 5 : standpipe; 6 : potential sliding surface; 7: controlling groundwater level

Fig. 1 Scheme of a practical siphon drain application

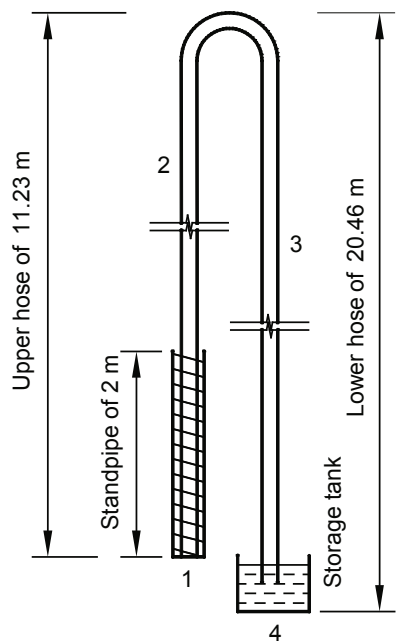

1: standpipe; 2: upper hose; 3: lower hose; 4: storage tank

Fig. 2 Schematic diagram of the experimental apparatus

\subsection{Test set-up}

The experimental apparatus consisted of a standpipe, an upper hose, a lower hose, and a storage tank (Fig. 2). The standpipe, with an elevation of $2.0 \mathrm{~m}$ and installed at the bottom of the upper hose, simulates the end of a borehole in practical engineering. The water level of the upper hose represents the actual slope water level. A siphon can reach a maximum rising water head of about $10.24 \mathrm{~m}$ under standard atmospheric pressure. Therefore, about $1.0 \mathrm{~m}$ of water in the standpipe remains once the elevation of the upper hose is set at $11.23 \mathrm{~m}$ (Fig. 2). The difference in elevation between the siphon vertex and the hose outlet was $20.46 \mathrm{~m}$. The outlet was placed in the storage tank. Siphon hoses with a series of diameters were used during the experiments. Based on observation, three typical kinds of polyurethane 
(PU) hoses with diameters of 4.0, 5.0, and $8.0 \mathrm{~mm}$, respectively, were tested.

\subsection{Siphon phenomena}

At first, the siphon hose was filled full of water and sealed at both ends. The two ends of the hose were dipped into the standpipe and the storage tank, respectively, to start the siphon drainage. Water was added to the standpipe to maintain a continuous siphon process, and then stopped after a few minutes, as a consequence of which, the water level decreased in the standpipe until the lift head reached the highest limit. Finally, water was added to the standpipe at different time intervals and different water-flow rates to investigate the flow characteristics.

The test showed that

1. In the upper hoses, we observed no hose-size bubbles (bubbles filling the entire section of the hose) in $8.0 \mathrm{~mm}$ siphon hoses, a few in $5.0 \mathrm{~mm}$ hoses, and more in $4.0 \mathrm{~mm}$ hoses (Fig. 3a).

2. In the lower hoses, slug flow with different degrees of stability was found in hoses with diameters of 4.0, 5.0, and $8.0 \mathrm{~mm}$. Fig. $3 \mathrm{~b}$ shows the slug flow in a $4.0 \mathrm{~mm}$ lower hose.

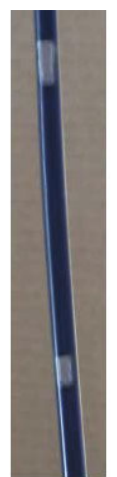

(a)

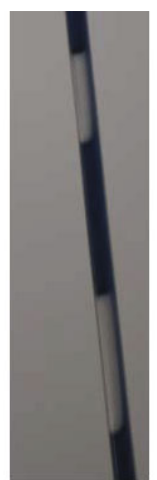

(b)
Fig. 3 Bubbles in $4.0 \mathrm{~mm}$ PU hoses

(a) Bubbles in upper hose; (b) Bubbles in lower hose

3. After the siphon process, similar moisture distribution characteristics in both upper and lower hoses were observed. A small length of no-water section was found near the vertex of the upper hose, and a much longer no-water section in the lower hose. These were caused by the existence of elevation differences of over $20 \mathrm{~m}$. The heights of full-water sections in both hoses were nearly the same.

4. After the siphon process, the bubbles in $8.0 \mathrm{~mm}$ hoses rose to the vertex and accumulated in less than $5.0 \mathrm{~min}$. In $5.0 \mathrm{~mm}$ hoses, the bubbles re- mained for about $24 \mathrm{~h}$ before becoming entirely accumulated at the top. However, in the $4.0 \mathrm{~mm}$ hoses, full-hose bubbles were sealed between the water columns after $7 \mathrm{~d}$.

\subsection{Flow characteristics at vertex of siphon hoses}

In slope engineering, the intensity and duration of rainfall determine the rising rate of the slope groundwater level and the flow velocity in the siphon drains. Therefore, in lab testing, different rainfall conditions can be simulated by adding water to the standpipe at different rates. Heavy rainfall can be simulated by adding water rapidly, while slowly dripping water at a rate of $700 \mathrm{ml} / \mathrm{h}$ and $400 \mathrm{ml} / \mathrm{h}$ simulates weak groundwater replenishment in dry seasons. In the case of rapid addition, 5.0 L water was added in $30 \mathrm{~s}$, while in the case of slow dripping, rates of $700 \mathrm{ml} / \mathrm{h}$ and $400 \mathrm{ml} / \mathrm{h}$ were adopted over a duration of $5.0 \mathrm{~h}$.

Tests were conducted using hoses of 4.0, 5.0 and $8.0 \mathrm{~mm}$ diameter. Table 1 and Figs. $4 \mathrm{a}-4 \mathrm{c}$ show in detail the distinct differences in flow characteristics at the vertex of the different siphon hoses during drainage. Rapid water addition led to a fast water level rise in the standpipe and a large flow rate in the siphon hoses at the vertex. In the 4.0 and $5.0 \mathrm{~mm}$ siphon hoses, a section of the water column passed through the vertex quickly and then fell down under gravity to generate slug flow, producing gas columns alternating with water columns (Fig. 4b). The slug flow was able to push the bubbles together with water to the outlet to prevent air accumulation in the siphon drainage. However, in the $8 \mathrm{~mm}$ hoses, most cases showed incomplete slug flows, with water channeling beneath the bubbles (Fig. 4c), which could not achieve an associated movement of air and water. Further increases in the flow rate could also lead to complete slug flow in $8.0 \mathrm{~mm}$ hoses.

Table 1 Flow characteristics at the vertex of siphon hoses during drainage

\begin{tabular}{cccc}
\hline \multirow{2}{*}{ Flow rate } & \multicolumn{3}{c}{ Flow characteristics } \\
\cline { 2 - 4 } & $8.0 \mathrm{~mm}$ & $5.0 \mathrm{~mm}$ & $4.0 \mathrm{~mm}$ \\
\hline Rapid addition & $\begin{array}{c}\text { Incomplete } \\
\text { of water } \\
700 \mathrm{~mL} / \mathrm{h}\end{array}$ & Slug flow & Slug flow \\
& Wall pressing & Wall pressing & Substantially \\
& flow & $\begin{array}{c}\text { flow and slug } \\
\text { flow }\end{array}$ & slug flow \\
$400 \mathrm{~mL} / \mathrm{h}$ & Wall pressing & Wall pressing & Substantially \\
& flow & flow & slug flow \\
\hline
\end{tabular}



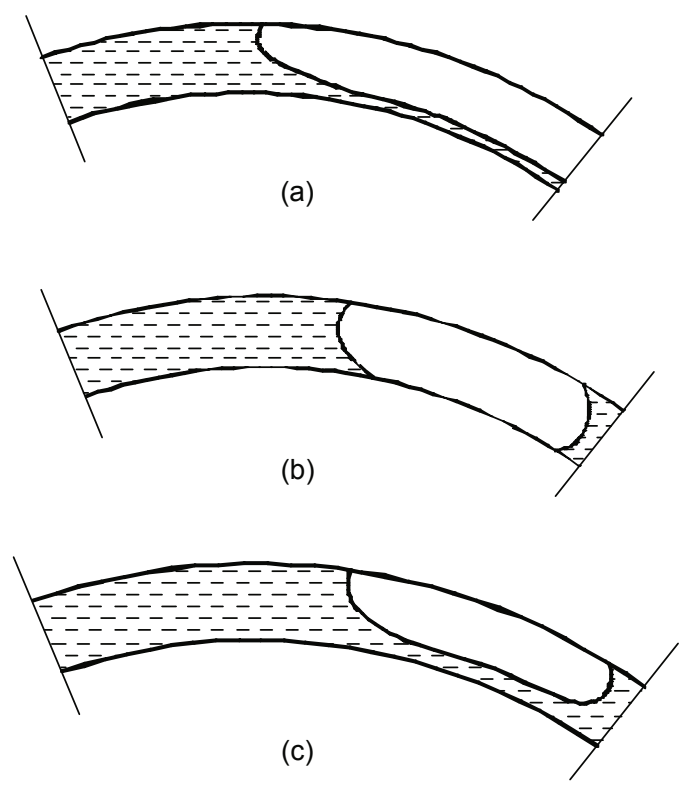

Fig. 4 Three types of flow at the vertex of hoses (a) Wall pressing flow; (b) Slug flow; (c) Incomplete slug flow

When the flow rate of water in the standpipe decreased to $700 \mathrm{ml} / \mathrm{h}$, the water level remained around the siphon launching level and the flow velocity in the upper hose remained low. For a hose with a diameter of $8.0 \mathrm{~mm}$, the slow increase in water level in the upper hose finally led to wall pressing flow, after water passed through the vertex into the lower hose (Fig. 4a). Wall pressing flow is more likely to discharge water without air. In this situation, the supplementary water separates increasingly more air in the low pressure area without water flow, and reduces the degree of vacuum within the hose. If the situation lasts long, it will ultimately lead to a complete stop of the siphon process. For $5.0 \mathrm{~mm}$ hoses, the $700 \mathrm{ml} / \mathrm{h}$ flow rate sometimes produced wall pressing flow and slug flow, demonstrating its threshold status. With a further decrease in the flow rate to about $400 \mathrm{ml} / \mathrm{h}$, slug flow appears. For $4.0 \mathrm{~mm}$ hoses, both $700 \mathrm{ml} / \mathrm{h}$ and $400 \mathrm{ml} / \mathrm{h}$ flow rates could form slug flow in the lower hose and achieve air discharge.

\subsection{Surface shape for wall pressing flow}

Tests showed that the surface shapes that tended to form wall pressing flow could be divided into two categories (Figs. 5a and 5b).

In the case of $8.0 \mathrm{~mm}$ hoses, the water level in the upper hose rose slowly to the vertex of the siphon hose and a stable stratified surface was observed. This shape was easily collapsed by water flowing along the hose wall when dropping into the lower hose in the form of wall pressing flow (Fig. 5a).

Fig. $5 \mathrm{~b}$ shows another case of wall pressing flow. When the siphon drainage process came to an end, the flow rate at the vertex became slower. In such a situation, a water film at the hose bottom may degenerate wall pressing flow. However, for slope drainage engineering, the siphon interval is long enough for the water film to evaporate and for some other physical interactions to occur. Therefore, siphon flow is less influenced by this category of wall pressing flow.

Thus, it can be seen from the tests that the water flow in larger diameter siphon drains is more likely to generate wall pressing flow and cause air accumulation at the top of the hose under a long period of inadequate water supply. The increasing air pressure at the top is associated with a decreasing siphon delivery lift, and finally terminates the entire siphon process. So it is important to conduct theoretical research on the causes of wall pressing flow and the threshold status of surface shapes (Fig. 5a).

(a)

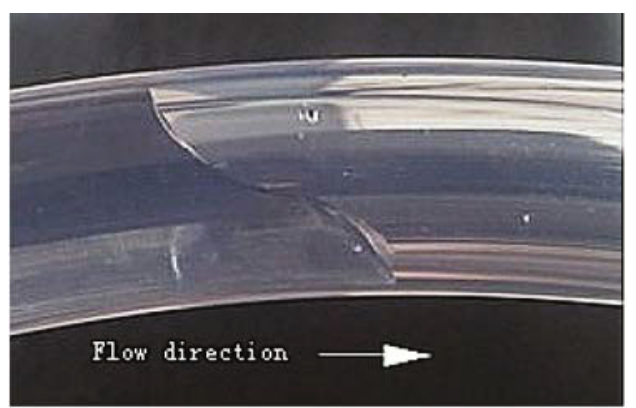

(b)

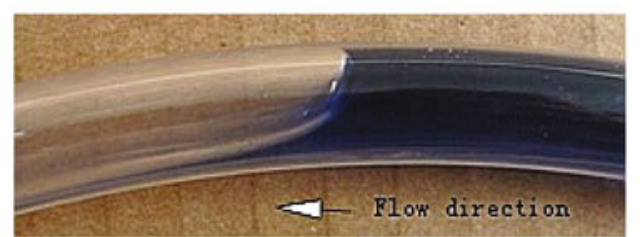

Fig. 5 Two surface shape categories leading to wall pressing flow

(a) Surface shape at the vertex of the $8.0 \mathrm{~mm}$ siphon hose; (b) Surface shape when there is a water film at the bottom of the hose

\section{Relationship between flow pattern and hose diameter}

A hose with a large diameter generates effective siphon drainage (Kong, 2004; Taha and Cui, 2004). 
So it is better to choose hoses with a diameter as large as possible under the premise of a long-term effective siphon. From previous sections, we conclude that siphon hoses are more likely to generate slug flow and show no air accumulation when the siphon drainage has high flow velocity (Wallis, 1969; Jiao et al., 2009). However, the flow velocity in siphon drainage for slope engineering is generally very low. Therefore, attention should be paid to the siphon flow at low velocity in the current study.

\subsection{Analytical model}

For a siphon drain with a low flow rate, the velocity of the flow in the upper hose is low enough to ignore its dynamic influence during a short period (Bretherton, 1961). Therefore, it is reasonable to adopt a hydrostatic analysis method.

Note that the flow characteristics at the top are also influenced by the radius of curvature at the vertex of the siphon hose. The actual elbow at the top of the hose is an arc-shaped curve. However, as addressed in previous sections, the slope in engineering scale is in practice much larger than the geometrical size of the hose cross-section. Therefore, the radius of curvature at the vertex of the siphon hose was assumed to be infinite in the current study. Thus, we can simplify the calculation model to the derivation of gas-liquidsectional shape in a horizontal hose.

Set the flow direction as $y$, vertical downward direction as $x$, and the perpendicular direction into the paper as $z$ (Figs. 6a and 6b). The original point is located at the center of the hose section. Every infinitesimal element $\mathrm{d} z$ in the $z$ direction has a similar surface shape, and thus has less impact on the water surface than those in the other two directions. Take a $\mathrm{d} z$ element near the original point, and simplify the $3 \mathrm{D}$ model to a $2 \mathrm{D}$ one, which is equivalent to the derivation of the gas-liquid-sectional shape between two flats.

\subsection{Water surface}

The Gibbs free energy of a curved surface liquid is (Wandelt 2012)

$$
G=-T S+P V+\sigma A,
$$

where $\sigma$ denotes the surface tension coefficient, and $G, T, S, P, V$, and $A$ denote the Gibbs free energy, temperature, entropy, pressure, volume, and area, respectively.

Taking gravitational potential energy into consideration, the total energy expression is (Tang et al., 2009)

$$
E_{\mathrm{t}}=G+E_{\mathrm{g}}=-T S+P V+\sigma A+m g h,
$$

where $E_{\mathrm{t}}$ and $E_{\mathrm{g}}$ denote the total energy and gravitational potential energy, respectively; $m, g$, and $h$ denote mass, gravity acceleration, and height, respectively.

Static water head is isothermal, isentropic and isobaric and incompressible. So we can neglect the invariants in Eq. (2) to obtain

$$
E_{\mathrm{v}}=\sigma A+m g h=\sigma_{\mathrm{lg}} A_{\mathrm{lg}}+\sigma_{\mathrm{sl}} A_{\mathrm{sl}}+\sigma_{\mathrm{sg}} A_{\mathrm{sg}}+\rho g V h,
$$

where $E_{\mathrm{v}}$ denotes the variable energy, $\sigma_{\mathrm{gg}}, \sigma_{\mathrm{s}}$, and $\sigma_{\mathrm{sg}}$ respectively denote the surface tension coefficients of gas-liquid, solid-liquid, and solid-gas (Zhu et al., 2007; Jumars, 2013). Similarly, $A_{\mathrm{lg}}, A_{\mathrm{sl}}$, and $A_{\mathrm{sg}}$ denote the contact area between gas and liquid, solid and liquid, solid and gas, respectively; $\rho$ denotes the density of water.

According to the principle of minimum potential energy, when the value of $E_{\mathrm{v}}$ in Eq. (3) approaches the minimum value, the water surface keeps stable.

By ignoring the influence from the $z$ direction, we simplify the 3D model into a 2D model (Fig. 7). For a section with a length of $2 a$, the area is $s=2 a r$, where $r$ denotes the radius of the hose. Assuming the functional expression as $y=f(x)$, the surface area and the volume can be simplified to be $l \mathrm{~d} z$ and $s \mathrm{~d} z$, respectively. After dividing by dz, Eq. (3) can be written as

$$
\begin{aligned}
E_{\mathrm{v}} / \mathrm{d} z= & \sigma l+\rho g s h=\sigma_{\mathrm{lg}} l_{\mathrm{lg}}+\sigma_{\mathrm{sl}} l_{\mathrm{sl}}+\sigma_{\mathrm{sg}} l_{\mathrm{sg}}+\rho g s h \\
= & \int_{-r}^{r}\left[\sigma_{\mathrm{lg}} \sqrt{1+y^{\prime 2}}+\rho g(r-x)(y+a)\right] \mathrm{d} x \\
& +\int_{-r}^{r}\left[\frac{1}{r}\left(\sigma_{\mathrm{sl}}-\sigma_{\mathrm{sg}}\right)\left(y+x y^{\prime}\right)\right] \mathrm{d} x+2 a\left(\sigma_{\mathrm{sl}}+\sigma_{\mathrm{sg}}\right),
\end{aligned}
$$

where $l_{\mathrm{lg}}, l_{\mathrm{sl}}$, and $l_{\mathrm{sg}}$ denote the contact lengths between gas and liquid, solid and liquid, and solid and gas, respectively, and $s$ denotes the water area within the section.

The boundary conditions satisfy

$$
s=\int_{-r}^{r}(y+a) \mathrm{d} x=2 a r \Rightarrow \int_{-r}^{r} y \mathrm{~d} x=0 .
$$


When $x= \pm r$, the moveable boundary condition can be expressed as (Lao, 2007)

$$
\left.\left[F+\left(\psi^{\prime}-y^{\prime}\right) F_{y^{\prime}}\right]\right|_{x= \pm r}=0
$$

where $F(x)$ is the function within the integral shown in Eq. (7), and $\psi(x)$ is the known curve corresponding to the horizontal line of the hose wall under the actual conditions.

According to Eqs. (4) and (5), we obtain:

$$
\begin{gathered}
F\left(x, y, y^{\prime}, \lambda\right)=\sigma_{\mathrm{lg}} \sqrt{1+y^{\prime 2}}+\rho g(r-x)(y+a) \\
+\frac{1}{r}\left(\sigma_{\mathrm{sl}}-\sigma_{\mathrm{sg}}\right)\left(y+x y^{\prime}\right)+\lambda y,
\end{gathered}
$$

where $\lambda$ is the Lagrange multiplier.

So the unsolved question changes to find the extremal curve of the function $J=\int_{-r}^{r} F \mathrm{~d} x$. Its Euler equation follows:

$$
F_{y}-\frac{\mathrm{d}}{\mathrm{d} x} F_{y^{\prime}}=0
$$

Substituting $F\left(x, y, y^{\prime}, \lambda\right)$ into Eq. (8), we can obtain:

$$
\begin{gathered}
\rho g(r-x)+\frac{1}{r}\left(\sigma_{\mathrm{sl}}-\sigma_{\mathrm{sg}}\right)+\lambda \\
=\frac{\mathrm{d}}{\mathrm{d} x}\left[\sigma_{\mathrm{lg}} \frac{y^{\prime}}{\sqrt{1+y^{\prime 2}}}+\frac{x}{r}\left(\sigma_{\mathrm{sl}}-\sigma_{\mathrm{sg}}\right)\right], \\
\sigma_{\mathrm{lg}} \frac{y^{\prime}}{\sqrt{1+y^{\prime 2}}}=-\frac{1}{2} \rho g x^{2}+(\rho g r+\lambda) x+C_{1}, \\
\sigma_{\mathrm{lg}} \frac{y^{\prime \prime}}{\left(1+y^{\prime 2}\right)^{3 / 2}}=\rho g(r-x)+\lambda,
\end{gathered}
$$

where $\sigma_{\mathrm{lg}}$ denotes the gas-liquid surface tension coefficient, and $C_{1}$ is a constant number.

The above equations can be considered as the curvature expressions of $y=f(x)$. Take $y^{\prime}=\tan \varphi$ as the slope at a certain point on the curve, where $\varphi$ is the intersection angle between the tangent line and the $x$ axis. Substituting this into Eq. (10) leads to

$$
\sigma_{\lg } \sin \varphi=-\frac{1}{2} \rho g x^{2}+(\rho g r+\lambda) x+C_{1}
$$

The moveable boundary condition shown in Eq. (6) is satisfied when $x= \pm r$, where $\psi(x)$ is the known curve corresponding to the horizontal line of the hose wall under the actual conditions. Therefore, we have shown that $\psi^{\prime}=\infty$. When $x=r$, Eq. (6) can be written as

$$
\begin{aligned}
& \sigma_{\mathrm{lg}} \sqrt{1+y^{\prime 2}}+\frac{1}{r}\left(\sigma_{\mathrm{sl}}-\sigma_{\mathrm{sg}}\right)\left(y+r y^{\prime}\right)+\lambda y \\
& +\left(\psi^{\prime}-y^{\prime}\right)\left[\sigma_{\mathrm{lg}} \frac{y^{\prime}}{\sqrt{1+y^{\prime 2}}}+\sigma_{\mathrm{sl}}-\sigma_{\mathrm{sg}}\right]=0 .
\end{aligned}
$$

Since $\psi^{\prime}=\infty$, we have

$$
\begin{gathered}
\sigma_{\mathrm{lg}} \frac{y^{\prime}}{\sqrt{1+y^{\prime 2}}}+\sigma_{\mathrm{sl}}-\sigma_{\mathrm{sg}}=0, \\
\sin \varphi(r)=\frac{\sigma_{\mathrm{sg}}-\sigma_{\mathrm{sl}}}{\sigma_{\mathrm{lg}}}=\cos \theta,
\end{gathered}
$$

where $\theta$ is the contact angle of the gas-liquid-particle three-phase system according to the Young equation (Wandelt, 2012).

Similarly, when $x=-r$, we have

$$
\begin{aligned}
& \frac{\sigma_{\mathrm{lg}}}{\sqrt{1+y^{\prime 2}}}+2 \rho g r(y+a)+\frac{1}{r}\left(\sigma_{\mathrm{sl}}-\sigma_{\mathrm{sg}}\right) y \\
& +\lambda y+\psi^{\prime}\left[\sigma_{\mathrm{lg}} \frac{y^{\prime}}{\sqrt{1+y^{\prime 2}}}-\sigma_{\mathrm{sl}}+\sigma_{\mathrm{sg}}\right]=0 \\
& \sin \varphi(-r)=\frac{\sigma_{\mathrm{sl}}-\sigma_{\mathrm{sg}}}{\sigma_{\mathrm{lg}}}=-\cos \theta
\end{aligned}
$$

Substituting Eqs. (15) and (17) into Eq. (12) shows

$$
\begin{aligned}
& \sigma_{\mathrm{lg}} \cos \theta=-\frac{1}{2} \rho g r^{2}+(\rho g r+\lambda) r+C_{1}, \\
& -\sigma_{\mathrm{lg}} \cos \theta=-\frac{1}{2} \rho g r^{2}-(\rho g r+\lambda) r+C_{1} .
\end{aligned}
$$

Therefore,

$$
\lambda=\frac{\sigma_{\mathrm{lg}}}{r} \cos \theta-\rho g r \quad \text { and } \quad C_{1}=\frac{1}{2} \rho g r^{2} .
$$


Subsequently, substituting Eq. (19) into the curvature expressions Eqs. (10) and (11) yields

$$
\begin{aligned}
& \sigma_{\lg } \frac{y^{\prime}}{\sqrt{1+y^{\prime 2}}}=-\frac{1}{2} \rho g x^{2}+\frac{\sigma_{\mathrm{lg}} \cos \theta}{r} x+\frac{1}{2} \rho g r^{2}, \\
& \sigma_{\lg } \frac{y^{\prime \prime}}{\left(1+y^{\prime 2}\right)^{3 / 2}}=-\rho g x+\frac{\sigma_{\mathrm{lg}}}{r} \cos \theta .
\end{aligned}
$$

Base on the previous derivations, when

$$
x=\frac{\lambda}{\rho g}+r=\frac{\sigma_{\mathrm{lg}}}{\rho g r} \cos \theta,
$$

the curvature becomes zero and $y^{\prime \prime}=0$. Thus, this point is the inflection point of the curve. When $\frac{\sigma_{\mathrm{lg}}}{\rho g r} \cos \theta \in[0, r]$, there must be an inflection point within the range of the hose diameter. Otherwise, when $\frac{\sigma_{\mathrm{lg}}}{\rho g r} \cos \theta>r, y^{\prime \prime}$ is always above zero in regard to the hose, thus a concave function within the diameter range. Thus, to define the curve shape in the hose, it is necessary to take the critical diameter and the critical radius into consideration.

The critical radius $r_{\mathrm{c}}$ shows that the curvature comes to zero when $x=r_{\mathrm{c}}$, therefore

$$
\begin{aligned}
& -\rho g r_{\mathrm{c}}+\frac{\sigma_{\mathrm{lg}}}{r_{\mathrm{c}}} \cos \theta=0, \\
& r_{\mathrm{c}}=\sqrt{\sigma_{\mathrm{lg}} \cos \theta /(\rho g)} .
\end{aligned}
$$

Figs. $6 \mathrm{a}$ and $6 \mathrm{~b}$ show the surface shapes when $r>r_{\mathrm{c}}$ and $r \leq r_{\mathrm{c}}$, respectively.

\subsection{Threshold diameter of siphon hose}

According to Eq. (23), it is possible to obtain the relationship between the contact angle $\theta$ and the threshold radius $r_{\mathrm{c}}$ (Fig. 7), where the surface tension coefficient between air and water is $\sigma_{\mathrm{gg}}=7.28 \times 10^{-2}$ $\mathrm{N} / \mathrm{m}$ under the normal temperature of $21{ }^{\circ} \mathrm{C}$. The water surface shapes (Fig. 6a) may collapse and flow along the wall of the hose when dropping into the lower hose as wall pressing flow (Fig. 4a), unable to discharge the accumulated air at the top of the hose. However, the water surface shown in Fig. $6 \mathrm{~b}$ has good integrity and is more likely to generate columnar water flow into the lower hose. Therefore, it will finally form slug flow and show gas columns alternating with water columns.
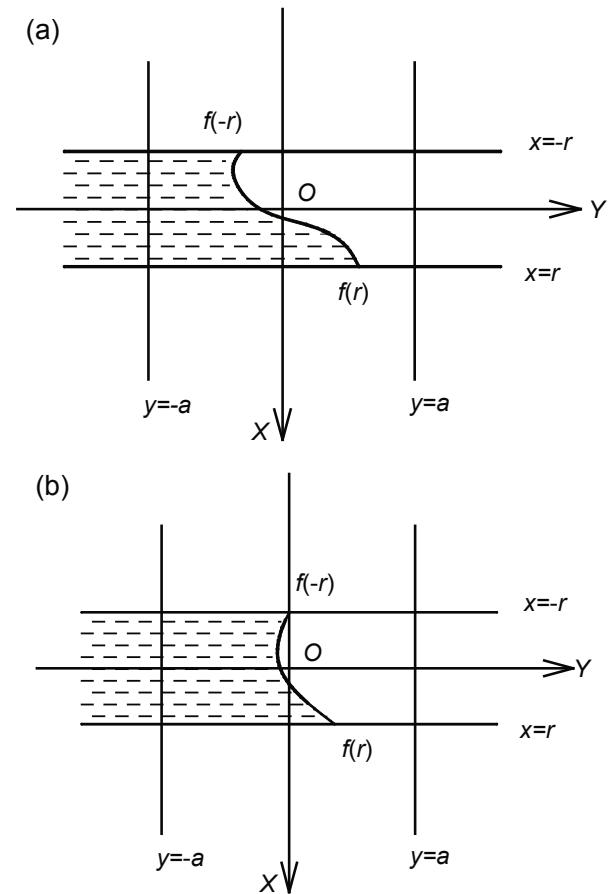

Fig. 6 Surface shapes for hoses with different diameters (a) $r>r_{\mathrm{c}}$; (b) $r \leq r_{\mathrm{c}}$

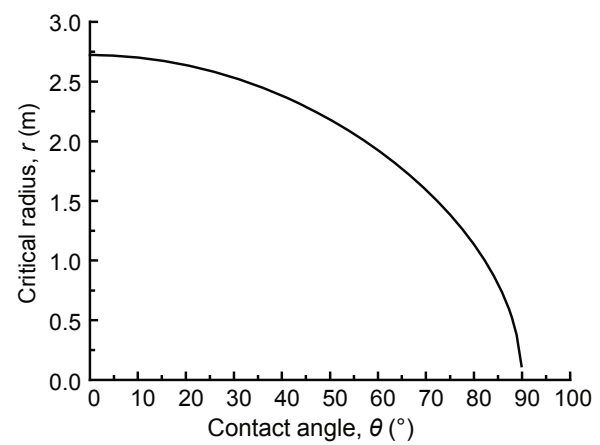

Fig. 7 Relationship between contact angle $\theta$ and critical radius $r_{\mathrm{c}}$

A typical PU siphon hose with a contact angle of $63^{\circ}$ was used in the present study (Barajas and Panton, 1993; Tretinnikov and Ikada, 1994; Hilpert, 2009). Therefore, the threshold radius from the formation of slug flow to wall pressing flow can be calculated as $r_{\mathrm{c}}=1.8 \mathrm{~mm}$. Analytically, the smaller the hose, the better the siphon process performs. Hence, smaller hoses are better. However, smaller pipes more easily become silted up by sand and soil, and may even cause air embolisms. The purpose of present 
study was to find an optimal value satisfying these two conflicting considerations. Therefore, hoses of $3.6 \mathrm{~mm}$ diameter are recommended.

\section{Conclusions}

In the present study, we investigated experimentally the flow pattern variables at the top of siphon hoses. The threshold conditions for terminating siphon process and automatically restarting were theoretically studied. The following conclusions can be made from the present experiments and theoretical analyses:

1. Low flow velocity leads to different flow patterns, such as slug flow and wall pressing flow, in siphon hoses of different diameter when water passes through the vertex of the hose. Slug flow can discharge bubbles together with water while wall pressing flow cannot.

2. Thermodynamic derivation revealed that hose diameter is the main factor influencing the flow pattern, and the threshold of hose diameter can be theoretically obtained. Wall pressing flow is more likely to be generated in the lower hose when $r>r_{\mathrm{c}}$, while complete slug flow can be generated when $r<r_{\mathrm{c}}$.

3. PU hoses with a diameter of $3.6 \mathrm{~mm}$ are recommended, to guarantee the long-term operation of siphon drainage.

Note that both the hose diameter and the hose number influence the drainage flow. The present study focused on how to obtain continuous siphon drainage, which is significantly affected by hose diameter. Once the diameter has been decided, we can adjust the hose number to satisfy the requirement of the drainage flow. Further research will be conducted in more complex situations and considering more influencing factors.

\section{References}

Barajas, A.M., Panton, R.L., 1993. The effects of contact angle on two-phase flow in capillary tubes. International Journal of Multiphase Flow, 19(2):337-346. [doi:10.1016/ 0301-9322(93)90007-H]

Bertolini, G., Guida, M., Pizziolo, M., 2005. Landslides in Emilia-Romagna region (Italy): strategies for hazard assessment and risk management. Landslides, 2(4):302-312. [doi:10.1007/s10346-005-0020-1]

Bomont, S., 2008. Back experience of deep drainage for landslide stabilization through lines of siphon drains and electro-pneumatics drains: a French railway slope stabilization example. In: Chen, J.Y., Zhang, J.M., Li, Z.K., et al. (Eds.), Landslides and Engineered Slope: from the Past to the Future, CRC Press, Boca Raton, USA, p.1713-1720. [doi:10.1201/9780203885284-c235]

Bretherton, F.P., 1961. The motion of long bubbles in pipes. Journal of Fluid Mechanics, 10(2):166-188. [doi:10. 1017/S0022112061000160]

Cambiaghi, A., Schuster, R.L., 1989. Landslide damming and environmental protection - a case study from Northern Italy. Proceedings of 2nd International Symposium on Environmental Geotechnology, Shanghai, China, 1:381385 .

Clark, A.R., Fort, D.S., Holliday, J.K., et al., 2007. Allowing for climate change; an innovative solution to landslide stabilisation in an environmentally sensitive area on the Isle of Wight. In: Mathie, E., McInnes, R., Fairbank, H., et al. (Eds.), Landslides and Climate Change: Challenges and Solutions. Book Series: Proceedings and Monographs in Engineering, Water and Earth Sciences, p.443-454. [doi:10.1201/NOE0415443180.ch52]

Gillarduzzi, A., 2008. Sustainable landslide stabilisation using deep wells installed with siphon drains and electropneumatic pumps. In: Chen, J.Y., Zhang, J.M., Li, Z.K., et al. (Eds.), Landslides and Engineered Slope: from the Past to the Future, CRC Press, Boca Raton, USA, p.1547-1552. [doi:10.1201/9780203885284 -c210]

Govi, M., 1989. The 1987 landslide on Mount Zandila in the Valtellina, Northern Italy. Landslide News, 3:1-3.

Hilpert, M., 2009. Effects of dynamic contact angle on liquid infiltration into horizontal capillary pipes: (semi)analytical solutions. Journal of Colloid and Interface Science, 337(1):131-137. [doi:10.1016/j.jcis.2009.04.013]

Jiao, B., Qiu, L.M., Lu, J.L., et al., 2009. Liquid film dryout model for predicting critical heat flux in annular two-phase flow. Journal of Zhejiang University-SCIENCE A, 10(3): 398-417. [doi:10.1631/jzus.A0820322]

Jumars, P.A., 2013. Boundary-trapped, inhalant siphon and drain flows: pipe entry revisited numerically. Limnology and Oceanography: Fluids and Environments, 3:21-39. [doi:10.1215/21573689-2082871]

Kong, L., 2004. Two-phase Fluid Mechanics. Higher Education Press, Beijing, China (in Chinese).

Lao, D.Z., 2007. Fundamentals of the Calculus of Variations (2nd Edition). National Defense Industry Press, Beijing, China (in Chinese).

Mao, Q.S., 1987. Deliberation of the relation between classification of aerating methods for high density fish farming and supersaturation of dissolved oxygen and a value range of air bubbles in the water. Fishery Machinery and Instrument, 4:3-5 (in Chinese).

Mrvik, O., Bomont, S., 2012. Experience with treatment of road structure landslides by innovative methods of deep drainage. In: Mambretti, S. (Ed.), Landslides, WIT Press, p.79-90. [doi:10.2495/978-1-84564-650-9/07] 
Sassa, K., 2005. Landslide disasters triggered by the 2004 Mid-Niigata Prefecture earthquake in Japan. Landslides, 2(2):135-142. [doi:10.1007/s10346-005-0054-4]

Shrestha, B.B., Nakagawa, H., Kawaike, K., et al., 2013. Glacial hazards in the Rolwaling valley of Nepal and numerical approach to predict potential outburst flood from glacial lake. Landslides, 10(3):299-313. [doi:10.1007/ s10346-012-0327-7]

Shu, Q., Zhang, W.D., 2005. Siphon method to discharge deep groundwater in landslide. Science and Technology of West China, 2005(10):10-12 (in Chinese).

Sun, H.Y., Wong, L.N.Y., Shang, Y.Q., et al., 2012. Experimental studies of groundwater pipe flow network characteristics in gravelly soil slopes. Landslides, 9(4):475-483. [doi:10.1007/s10346-011-0312-6]

Sun, H.Y., Xiong, X.L., Shang, Y.Q., et al., 2013. Pipe air accumulation causes and its control method in slope siphon drainage. Journal of Jilin University (Earth Science Edition), 44(1):279-285 (in Chinese).

Taha, T., Cui, Z.F., 2004. Hydrodynamics of slug flow inside capillaries. Chemical Engineering Science, 59(6):11811190. [doi:10.1016/j.ces.2003.10.025]

Tang, X.Z., Lu, L.P., Liu, G.L., et al., 2009. The variational approach to capillary action. College Physics, 28(4): 26-28 (in Chinese).

Tretinnikov, O.N., Ikada, Y., 1994. Dynamic wetting and contact angle hysteresis of polymer surfaces studied with the modified Wilhelmy balanced method. Langmuir, 10(5):1606-1614. [doi:10.1021/la00017a047]

Wallis, G.B., 1969. One-dimensional Two-phase Flow. McGraw-Hill, New York.

Wandelt, K., 2012. Surface and Interface Science. Wiley-VCH, Weinheim, Germany.

Yang, Y.Y., Yao, A.J., Zhang, Z.M., et al., 2009. Experimental study of controlling groundwater technology for bank slope. Rock and Soil Mechanics, 30(8):2281-2285 (in Chinese).

Zhang, Y.F., Zhang, C.L., 1999a. Experimental study of siphon drainage in Xiangqian line K93 road cutting landslide. Subgrade Engineering, 4:26-30 (in Chinese).

Zhang, Y.F., Zhang, Y.J., 1999b. Research on siphon drainage application technology. China Railway Science, 20(3): 52-60 (in Chinese).

Zhao, W.R., Shi, H.X., Wang, D.H., 2004. Modeling of mass transfer characteristics of bubble column reactor with surfactant present. Journal of Zhejiang University SCIENCE, 5(6):714-720. [doi:10.1631/jzus.2004.0714]

Zhu, F., Miao, R.C., Luo, D.B., 2007. Boundary reflection from the sunk curved liquid surface and its application. Chinese Journal of Quantum Electronics, 24(4):420-424 (in Chinese).

\section{中文概要：}

本文题目: 边坡高扬程虹吸排水管流态特征研究

An investigation of flow characteristics in slope siphon drains

研究目的: 从实验及理论角度阐述边坡高扬程虹吸排水容易断流造成虹吸中断的原因, 并提供解决方案, 实现虹吸排水的长期有效。

创新要点 : 利用物理模型实验, 结合理论解析推导, 得到了高扬程虹吸排水管顶部流态特征及其与管径 的关系，解决了高扬程虹吸排水容易断流造成虹吸中断问题，保证了虹吸排水技术在边坡治 理工程中的长期有效性。

研究方法 : 通过物理模型试验, 揭示虹吸水流经过管顶区段的三种流型特征 (见图4); 利用热力学理论

推导，得到了虹吸水流经过管顶区段由贴壁流向弹状流转变的临界管径，见公式（23）。

重要结论 : 管中形成气液共同移动的完整弹状流是实现虹吸排水长期稳定的关键, 虹吸水流经过管顶区 段由贴壁流向弹状流转变时存在临界管径。保证边坡工程中虹吸排水长期稳定的管径以 $3.6 \mathrm{~mm}$ 为宜。 